\title{
Maternal anaemia and pregnancy outcome: a descriptive study in rural areas of Kamrup District, Assam
}

\begin{abstract}
Background: The relationship between iron deficiency anaemia and low-birth-weight babies during pregnancy remains significant. Low birth weight babies are an increasing risk affecting infant mortality and poor developmental abilities is a rising concern. We aimed to identify the changes in hemoglobin level during pregnancy and study their impact on birth outcomes. This study aimed also to investigate and compare the prevalence of anaemic and non anaemic pregnant women in Boko Bongaon block, Assam in relation to maternal, antenatal and birth-associated factors.
\end{abstract}

Subject/Methods: The study setting is in a rural area of Boko-Bongaon, Kamrup situated $85 \mathrm{~km}$ away from Guwahati city. The Study design is a community based cross-sectional study done during the period from August 2012 to July 2013. A total of 160 pregnant women were selected by simple random sampling and data collected by house to house visit. Interview was conducted with the use of Predesigned, Pretested structured schedule.

Results: We analysed deliveries of 160 pregnant women of which 156 were full term births and 4 still births. There was a statistical significant association between anaemia and birth weight of the babies. Anaemia $(\mathrm{Hb}<11 \mathrm{~g} / \mathrm{dl})$, was prevalent in $86 \%$ of women, but was not significantly related to the birth outcomes.

Conclusion: The present study highlights the importance of regular monitoring of haemoglobin level at intervals during pregnancy to prevent anaemia. Future studies should explore other related risk factors and the reasons for poor birth outcomes in mothers in this population, to inform the design of appropriate public health policies that address this issue.
Volume 6 Issue 3 - 2020

\begin{abstract}
Moushumi Biswas,' Rupali Baruah²
'Assistant Professor, Department of Community medicine, Silchar Medical College, India

2Professor and Head, Department of Community Medicine, Assam Medical College, India
\end{abstract}

Correspondence: Moushumi Biswas, Assistant Professor, Department of Community medicine, Silchar Medical College, Silchar,Assam, India, Email moushumidr@gmail.com

Received: April 20, 2020 | Published: May 12, 2020

Keywords: anaemia, pregnancy, haemoglobin levels, birth outcome

Abbreviations: LBW, low birth weight; GDM, gestational diabetes mellitus; PET, preeclamptic toxaemia

\section{Introduction}

Iron deficiency anaemia is the common deficiency faced by women throughout their reproductive lives. ${ }^{1,2}$ Despite the high prevalence of iron deficiency anaemia in women, the condition is still under diagnosed and therefore undertreated, with serious clinical consequences. Pregnancy and lactation increases requirement for iron, and thus calls for medicinal iron supplementation. ${ }^{3}$ Women with heavy menstrual loss also requires additional iron than can reasonably be absorbed; thus, they often become iron deficient. World Health Organization (WHO) or World Health Statistics data shows that $40.1 \%$ of pregnant women worldwide were anaemic in 2016. According to the National Family health Survey - 4 fact sheet $47.6 \%$ of the pregnant women, aged 15-49 years are anaemic. It is one of the most common morbidities that affects health, education, productivity of the entire nation. ${ }^{4}$ The World Health Organisation has defined criteria for anaemia cut off as measured by the haemoglobin. ${ }^{5}$ The most common indicator of anaemia is iron deficiency and most widespread of all nutritional deficiencies in pregnancy. ${ }^{6}$ Anaemia is highly prevalent in India and contributes to about $80 \%$ of the maternal death due to anaemia in South Asia. ${ }^{7}$ Interestingly there is marginally decrease in prevalence of anaemia in pregnant women in India from $58 \%$ in National Family Health Survey-3 (2005-06) to $50 \%$ in National Family Health Survey - 4(2015-16). The present study conducted in the villages of Boko-Bongaon is inhabited by diverse population of ancient ethnic tribes and non tribes.

\section{Methodology}

a. Study design: This study is a Community based Cross sectional study under taken in Boko-Bongaon block of Kamrup, Assam. Boko-Bangaon Community Development Block is situated at $85 \mathrm{~km}$ west of Guwahati and forms one of the rural field practice area of department of Community Medicine of the Gauhati Medical College.

b. Study period: The study was carried from August 2012 to July 2013.

c. Villages and population: There are a total of 140 villages and 38 sub centers according to the list obtained from the Kamrup census office (2001 census).

d. Study population: Pregnant women in the third trimester of pregnancy (29-40 weeks of gestation) and the babies born to them.

e. Ethical clearance: Permission for the study was obtained from the Institutional Ethics committee (IEC) of Srimanta Sankardev University of Health Sciences, Narakasur Hill Top, Gauhati, Assam.

f. Study variable: Age, education, religion, caste, income, type of family, age at marriage, age at first pregnancy, gravida, parity, birth interval, haemoglobin.

g. Sample size: The sample size for the study was taken as 160 taking the prevalence of anaemia according to NFHS-4 fact sheet into account and permissible level of error as $10 \%$. 
h. Inclusion criterion: Women with confirmed pregnancy, 29-40 weeks of gestation, willing to participate.

i. Exclusion criteria: Pregnant women below 19 years of age, women with bleeding disorders, heart disease and hypertension, diabetes mellitus prior to pregnancy, Gestational diabetes mellitus (GDM), Rh-negative mother, Preeclamptic toxaemia (PET), antepartum haemorrhage, Eclampsia, Infective cause like malaria or tuberculosis, haemoglobinopathies Chronic illnesses.

j. Hemoglobin measurement: Anaemia was classified according to WHO criteria. Hemoglobin concentration of less than 11.0 $\mathrm{gm} / \mathrm{dl}$ was considered as an indication of indication of anemia. .Hemoglobin concentration of 10.0-10.9 gm/dl, 7.0-10.0 gm/dl and less than $7.0 \mathrm{gm} / \mathrm{dl}$ were considered to be mild, moderate and severe anaemia respectively.

During the interview, information on number of antenatal visits, place and mode of delivery were noted and anthropometric measurement like height and weight were taken. Dietary assessment was done within the 24-hour dietary recall method, with the help of food frequency questionnaire. The mother is given visit once and simultaneously, the neonatal outcome including length and weight were determined within 24 hours of delivery. The weight of the newborn was recorded with a weighing machine and length with a measuring tape nearest up to $0.1 \mathrm{~cm}$. Low birth weight was defined as a weight of less than 2500 grams $(<2.5$ Kilograms $)$ recorded immediately after birth. In some situation where the baby could not

Table I Distribution of pregnant women according to haemoglobin in gm/dl

\begin{tabular}{lll}
\hline Hb in gm/dl & \multicolumn{2}{l}{ Pregnant women } \\
\hline \multirow{2}{*}{ Number } & Percentage \\
$* \geq$ I I (No Anaemia) & 21 & $86.88 \%$ \\
Total & 139 & $13.12 \%$ \\
\hline
\end{tabular}

*Criteria of anaemia in pregnant women as per WHO (2002)

Cut off level: $<1 \mathrm{Igm} / \mathrm{dl}$ is anaemia, $\geq 1 \mathrm{Igm} / \mathrm{dl}$ is no anaemia

Table 2 Distribution of anaemia in pregnant women by registration, ANC visits and IFA tablet consumption

\begin{tabular}{|c|c|c|c|c|c|c|c|}
\hline \multirow[t]{2}{*}{$\begin{array}{l}\text { Ante-natal } \\
\text { care }\end{array}$} & \multicolumn{2}{|c|}{ Anaemia $(n=139)$} & \multicolumn{2}{|c|}{ No anaemia $(n=2 I)$} & & \multirow{2}{*}{$\begin{array}{l}\text { Significance } \\
P=0.045\end{array}$} \\
\hline & Number & Percentage & Number & Percentage & Number & Percentage & \\
\hline Availed & 127 & $91.37(96.21)$ & 5 & $23.80(3.78)$ & 132 & 82.5 & \\
\hline \multirow[t]{2}{*}{ Not availed } & 12 & $8.63(42.85)$ & 16 & $76.19(57.14)$ & 28 & 17.5 & \\
\hline & \multicolumn{6}{|c|}{ Receipt of IFA tablets } & \\
\hline Received & 64 & $46.04(83.12)$ & 13 & $61.90(16.88)$ & 77 & 88.75 & $P=0.023$ \\
\hline Not received & 75 & $53.96(90.36)$ & 8 & 38.09 (9.63) & 83 & 11.25 & \\
\hline
\end{tabular}

Table 3 Distribution of anaemia by delivery outcome

\begin{tabular}{|c|c|c|c|c|c|c|c|}
\hline \multirow{2}{*}{$\begin{array}{l}\text { Delivery } \\
\text { Outcome }\end{array}$} & \multicolumn{2}{|c|}{ Anaemia $(n=139)$} & \multicolumn{2}{|c|}{ No anaemia $(n=2 I)$} & \multicolumn{2}{|l|}{ Total } & \multirow{2}{*}{$\begin{array}{l}\text { Significance } \\
P=0.0135\end{array}$} \\
\hline & Number & Percentage & Number & Percentage & Number & Percentage & \\
\hline Live baby & 135 & 97.12 & 21 & 100 & 156 & 97.5 & \\
\hline IUD/Still birth & 4 & 2.87 & 0 & & 4 & 2.50 & \\
\hline
\end{tabular}

be seen immediately after delivery, weight was determined based on information and hospital records. Interviewing the subjects by using pre-designed, pre-tested structured schedule collected Iron-Folic Acid tablets supplementation.

\section{Results}

A total of 160 mothers were interviewed with house to house has been classified according to the WHO criteria. The prevalence ana in the present study was found to $86.88 \%$ (139 mothers) (Table 1). The present study also reported that out of 139 anaemic pregnant women $91.37 \%$ registered and availed antenatal care. Ou of 28 pregnant women who did not avail antenatal care $12(8.63 \%)$ were anaemic. There is a significant association of anaemia with the availability of antenatal care. Out of 139 anaemic women, 53.96\% women didnot receive IFA tablets whereas 46.04\%women received IFA tablets (Table 2).

Out of 160 deliveries there are 156 live births and 4still birth. Again out of 156 live births, $135(97.12 \%)$ babies are born out of anaemic (Table 3$)$. Out of 156 deliveries, 91 (58.33\%) were male and $65(41.66 \%)$ were females (Table 4$)$. There were $56(41.48 \%)$ of women among the anaemic mothers who gave birth to low birth weight babies compared to $79(56.83 \%)$ women who had normal birth weight babies.5 (23.81\%) of the non-anaemic mothers gave birth to low birth weight babies in comparison to $16(76.19 \%)$ normal birth weight babies. There is significant association of anaemia with low birth weight of the babies $(\mathrm{P}=0.0462)$ (Table 5). 
Table 4 Distribution of pregnant women according to the delivery outcome

\begin{tabular}{lll}
\hline Infants born (gender) & Number & Percentage \\
\hline Male & 91 & 58.33 \\
Female & 65 & 41.66 \\
Total & 156 & 100 \\
\hline
\end{tabular}

Table 5 Distribution of pregnant women according to the birth weight of the babies

\begin{tabular}{|c|c|c|c|c|c|c|c|}
\hline \multirow[t]{2}{*}{ Birth weight of the baby $(\mathrm{kg})$} & \multicolumn{2}{|c|}{ Anaemia $(n=139)^{*}$} & \multicolumn{2}{|c|}{ No Anaemia $(n=2 I)$} & \multicolumn{2}{|l|}{ Total } & \multirow{2}{*}{$\begin{array}{l}\text { Significance } \\
P=0.0462\end{array}$} \\
\hline & Number & Percentage & Number & Percentage & Number & Percentage & \\
\hline Low birth weight (LBW) & 56 & 41.48 & 5 & 23.81 & 61 & 38.12 & \\
\hline Normal birth weight (NBW) & 79 & 58.51 & 16 & 76.19 & 95 & 59.37 & \\
\hline
\end{tabular}

\section{Discussion}

Iron deficiency anaemia still remains a major public health concern affecting mothers and children. ${ }^{8}$ The prevalence of anaemia among pregnant women in Boko Bongaon region was found to be $86.88 \%$. According to a report from WHO or UNICEF the problem of anaemia is intense in a community when the occurance rate exceed $40 \%$. Similar Studies have been conducted in different parts of India and finding the prevalence of anaemia in pregnant women and its associated factors. ${ }^{9,10}$ The above studies carried out in different parts of the country vary greatly and this discrepancy may be due to variable criteria of haemoglobin adopted for the detection of anaemia, diet which may be associated with religion, social customs, geographical and environmental factors. We have demonstrated in our previous study that oral consumption of iron is effective in correcting anaemia.

In the present study we have demonstrated that there is a significant association between anaemia and availability of antenatal care. Although free ante-natal checkups and Iron and Folic acid tablets are provided to pregnant women, we found that $82.50 \%$ of women got regular ANC checkups as advised by doctor and only $46.04 \%$ of anaemic pregnant females took IFA tablets. This study is comparable to Chabbra .S et al, 1998 where $52 \%$ of the pregnant women were registered and rest $48 \%$ did not. ${ }^{11}$ In another study by P.K. Mony et al, 2001 found $87.2 \%$ of mothers took IFA tablets while $12.8 \%$ did not IFA tablet. ${ }^{12}$ We found that in anemic mothers, $97.12 \%$ gave birth to live births and $2.87 \%$ gave birth to still babies. On the other hand, in 21 non - anemic mothers, all 21 (100\%) mother gave birth to live babies. The present study also shows that $40.28 \%$ of the anaemic mothers give birth to low birth babies and $56.23 \% \%$ had normal weight babies; For non anaemic mothers, 23.81\% were low birth weight and $76.19 \%$ were normal weight babies. Similar Studies has been demonstrated before by Pankajet al, 2012 Nair M et al, where mothers with anaemia at any time during pregnancy was found to have 4.3 times higher risk of giving birth to low birth weight babies compared to non-anemic mothers. ${ }^{13,14}$ Lone et al, 2005 also found the risk of low birth weight among anaemic mothers than nonanaemic. ${ }^{15}$ Levy A. et al, 2005 reported that higher rate of low birth weight babies (LBW) were found among patients with anaemia as compared to non anaemic women. ${ }^{16}$

Thus anaemia continues to be endemic among pregnant women in India, despite the intervention measures like distribution of IFA tablets. Lower anaemia prevalence was observed among women taking iron supplementation. Some of the reasons that iron supplementation programme are ineffective may be that the health workers engaged in villages (field) are not adequately motivated for effective distribution and improving compliance by pregnant women. The low compliance is mainly due to the side effect associated with iron preparations.
There was mistake in the part of the health care provider who failed to supply the pregnant women with adequate iron and folic acid .The presence of anaemia in pregnant women may be due to inadequate and irregular supply of iron and folic acid.

\section{Conclusion}

The focus of this community-based study is to make the pregnant women of rural areas aware of anaemia during pregnancy and its significant health consequences on the newborn. Only a relatively few community-based studies on maternal anaemia and foetal outcome have been published until recently in India. Our society is also ignorant of women's health and future consequence of anaemia during pregnancy and child birth. The health providers in the village also fails to recognize this significant health problem and the future impact of anaemia on the foetus. Although many programs and projects have been launched to prevent and control anaemia, still the results are unsatisfactory. At the field level haemoglobin estimation is the only method available diagnosis of anaemia besides clinical assessment. Many hospital-based studies on anaemia have been done but very few community-based studies have been done. This study will throw a light in planning future intervention strategies to prevent and control anaemia. Haemoglobin measurement is a sensitive indicator for anaemia and in future also this tool will help in detectionand prevention of anaemia in pregnancy.

\section{Acknowledgments}

We express our gratitude to the pregnant mothers of BokoBongaon in rural Kamrup who gave their time in this study.

\section{Conflicts of interest}

Author declare that there is no conflict of interest.

\section{Funding}

This study was supported by MD/MS thesis grant for medical students in North East region, DBT, GOI under TU for financial support.

\section{References}

1. Fadi G Mirza, Rezan Abdul-Kadir, Christian Breymann, et al. Impact and Management of Iron Deficiency and Iron Deficiency in Women's Health. Expert Rev Hematol. 2018;11(9):727-736.

2. Laura Percy, Diana Mansour. Iron deficiency and iron deficiency anaemia in women. Scand J Clin Lab Invest Suppl. 2017;19:155-161. 
3. Chander Shekhar Gautam, Lekha Saha, Kavita Sekhri, et al. Iron Deficiency in Pregnancy and the Rationality of Iron Supplements Prescribed During Pregnancy. Medscape J Med. 2008;10(12):283.

4. Slotzfus RJ, Dreyfuss ML. Guidelines for the Iron supplement to prevent and treat iron deficiency anaemia. 1998.

5. WHO/UNICEF/UNU. Iron deficiency anaemia assessment prevention and control; A Guide for program managers. Geneva; 2001.

6. WHO. Maternal Health and Safe Motherhood Programme, Nutrition. The prevalence of anaemia in women: A tabulation of available information, 2nd ed. Geneve; 2012

7. Ezzati M, Lopez AD, Rodgers AA, et al. Comparative quantification of health risks: global and regional burden of disease attributable to selected major risk factors. Geneva, Switzerland; 2004.

8. MD Cappellini, K M Musallam, AT Taher. Iron deficiency anaemia revisited. J Intern Med. 2020;287(2):153-170.

9. Mohammad Zahid Siddiqui, Srinivas Goli, Tamal Reja, et al. Prevalence of and Its Determinants Among Pregnant, Lactating, and Nonpregnant Nonlactating Women in India. SAGE. 2017;7(3).
10. Naimo Khalif Mahamoud, Bashir Mwambi, Caesar Oyet, et al. Prevalence of anemia and socio-demographic factors associated with anemia among pregnant women attending antenatal Hospital in Jaipur City, India. $J$ Blood Med. 2020;11:13-18.

11. Kapur D, Agarwal KN, Agarwal DK. Nutritional anaemia and its control. Indian J Paediatrics. 2002;69(7);607-609.

12. PK Mony, L Verghese, S Bhatacharji, et al. Demography, Environmental status and Maternal Health Care in Slums of Vellore Town, Southern India. Indian Journal of Community Medicine. 2006;31(4).

13. Pankaj Kumar, Prasad Pore, Usha Patil. Maternal anaemia and its Perinatal outcome in a tertiary care hospital in Pune, Maharastra. Indian Journal of Basic and Applied Research. 2012:2(1);111-119.

14. Nair M, Gireesh S, Yakoob R, et al. Effect of maternal anaemia on birth weight of term babies. Int J Contemp Pediatr. 2018;5(3):1019.

15. Lone FW, Quershi RN, Emanuel F. Maternal anaemia and its impact on perinatal out come. Trop Med Int Health . 2004;9(4),277:973-976.

16. Levy A, Fraser D, Katz M, et al. Maternal anaemia during pregnancy is an independent rsk factor for low birth weight and preterm delivery. Eur J Obstet Gynaecology Reproductive Biol. 2005;122(2):182. 